\title{
Products Produced from Organic Waste Using Managed Ecosystem Fermentation
}

\author{
Edward A. Calt ${ }^{1}$ \\ ${ }^{1}$ President of Integrated BioChem, LLC, Raleigh, USA \\ Correspondence: Edward A. Calt, President of Integrated BioChem, LLC, 3221 Blue Ridge Road, Suite 105, \\ Raleigh, North Carolina 27612, USA. Tel: 1-919-844-2680. E-mail: ecalt@IntegratedBioChem.com
}

\author{
Received: February 16, 2015 Accepted: March 12, 2015 Online Published: May 14, 2015 \\ doi:10.5539/jsd.v8n3p43 \\ URL: http://dx.doi.org/10.5539/jsd.v8n3p43
}

\begin{abstract}
Biomass is the only renewable source of organic chemicals available. The Managed Ecosystem Fermentation process biologically converts organic waste into high value industrial chemicals over night. MEF modifies and regulates a process that has worked in nature for millions of years to extract valuable basic chemicals that are used in industry today, thereby converting the handling of waste from an expense to a source of revenue. MEF is the only known process that can convert cellulose into protein. Unlike most processes that produce a single product, the MEF produces a portfolio of products. MEF produces a portfolio of products ranging from enzymes, proteins and multiple long and short chain fatty acids. The MEF process is based on the microbial ecosystem in a ruminant animal. It is a multispecies process involving over 3,000 species of microbes simultaneously. It works because a multispecies system has more chemical pathways to breakdown the organic matter than a single species.
\end{abstract}

Keywords: amino acids, anaerobic digestion, biodiesel, fatty acids, fermentation, greenhouse gas, high protein animal feed, Managed Ecosystem Fermentation, microbial protein organic waste, oleochemicals, volatile fatty acids

Managed Ecosystem Fermentation (MEF) is a new manufacturing process that biologically converts cellulose and other organic materials into protein and high value industrial chemicals. It is a continuous, self-sustaining fermentation process that is focused on economics, resulting in a significant reduction in the energy required, thereby making the process environmentally and economically sustainable. The MEF process is capable of producing several thousand dollars of revenue per ton of organic waste.

One of the economic benefits of MEF is the ability to utilize vegetable wastes as feedstock; including food processing trims, olive pulp, fruit pulp from juicing, and many others. The MEF process utilizes an ecosystem of microbes found in the digestive tract of ruminant animals. This ecosystem of microbes is able to process and adapt to a wide variety of organic materials without sterilization and is stable for many years. MEF has adapted the rumen ecosystem to an industrial environment to extract a portfolio of high value products. The MEF process does not use any genetically modified organisms. It works with only naturally occurring organisms.

The disposal of organic waste has been and continues to be a significant and complex challenge faced by every society from both the environmental and economic perspectives. The toxic conditions created by the concentration of organic waste have been a plague on public health and welfare along with causing a significant deterioration of property values.

Organic waste provides a fertile breeding ground for disease vectors including flies, mosquitos, rats and mice. The diseases transmitted by these vectors include West Nile virus, equine encephalitis, dengue fever, yellow fever, malaria, sleeping sickness, hanta-virus pulmonary syndrome, lymphocytic choriomeningitis, salmonellosis, hemorrhagic fever, and diarrhea.

Additionally, the improper disposal of organic waste is a major source of ground water contamination containing pathogenic microbes spreading disease and death from the disposal site.

Further, greenhouse gasses produced by the uncontrolled decomposition of organic waste contribute to global warming while the noxious odors contribute to the destruction of the air quality.

Current methods of handling have four inherent problems. First, the elimination of our waste is expensive. Second, it contributes to the pollution of the land, water, and air. Third, it is a source of pathogenic disease vectors. Finally, most of the current methods of disposal fail to significantly reduce the volume of residue after treatment. 
Historically, three approaches to the disposal of organic waste have been used with varying rates of success. They include composting, burying, and burning. Today the economics and ecologic effects of these methods have made them unsatisfactory due to many factors arising around our ever increasing population.

Composting requires the close proximity between the location of consumption and production. Today and in the future, the logistics of returning the organic waste to the field is impractical and economically inefficient. Additionally, composting permits the release of greenhouse gases during the decomposition process.

Burying organic waste has become economically inefficient due to the increasing cost of land. It necessitates an ever-increasing amount of land for the disposal of the additional organic waste generated. Simultaneously, it depreciates the value of adjoining land, and creates environmental problems from the contamination of air and water.

Burning has recently been touted as a source of renewable energy. It is at best a cost offset in the waste removal process. The installation and maintenance of air scrubbers greatly decreases the economic returns from the process. This combined with the fact that over fifty percent of the inbound mass is water and must be burned off further contributes to the inefficiency of the process.

A fourth method of disposal now in use is anaerobic digestion (AD). In the developing world this makes methane as a fuel source economically available. The residual digestate can be reused as fertilizer in local agricultural production. However, in large urban settings the methane produced must now compete with other sources of supply for a market. As more shale gas comes on line providing a less expensive source of fuel, the investment of capital into anaerobic digestion facilities becomes less attractive as the product produced must now compete on price alone. Additionally, the disposal of the digestate from the process is now becoming more expensive and difficult as the residual volume is approximately $90 \%$ of the inbound feedstock. Additionally, digestate needs to be transported and stored until the application during the growing cycle of the particular crop.

Efficient organic waste disposal requires solving both the environmental and economic issues simultaneously. The environmental challenge deals with the mass and volume related to the organic waste. How can the waste be processed in a safe and economically sustainable manner? The second deals with the economics of the process. Can this "waste" material be converted into something that has much more value?

MEF represents a new approach to the disposal of organic waste. It is based on the concept that to be environmentally sustainable a process must be economically sustainable. With MEF, organic waste becomes the raw material that is converted into a revenue stream of high value products thereby converting a major expense into a source of revenue.

MEF uses the rumen derived from a ruminant animal (cow, goat, sheep, etc.) to provide the ecosystem at the heart of the process. This ecosystem of microbes consists of over 3,000 species of bacteria, yeast, fungi, and protozoa. The process works with a non-homogenous, non-sterile feedstock under non-sterile conditions. It is a process that adapts to changes in its feed. It works at about $40^{\circ} \mathrm{C}$ at ambient pressure. It is neither aerobic nor is it anaerobic; it requires some oxygen to survive. It can be operated over a range of pH's depending upon the desired output product/s. It works because the ecosystem itself is focused on its own survival. It works because a multispecies fermentation has more chemical pathways to breakdown and convert the biomass than a single species.

The difference between MEF and AD can best be explained in terms of the applicable thermodynamics. Both AD and MEF are exothermic processes. In both processes anaerobic microbes get their energy by breaking up longer hydrocarbon chains into smaller ones and depositing their waste hydrogen into the fragmented molecules. AD allows this molecular reduction to go to completion inside large digester tanks, reducing most of the volatile fatty acids into methane $\left(\mathrm{CH}_{4}\right)$, carbon dioxide $\left(\mathrm{CO}_{2}\right)$ with water $\left(\mathrm{H}_{2} \mathrm{O}\right)$ being released from within the cellulose. The primary agents for this are the methanogenic bacteria. Essentially the methanogenic bacteria are allowed to decompose the high-energy (high value) molecules to the lowest stable energy state (low value) possible. In general, the economics of carbon suggest the more carbon on the molecule the higher the value. In contrast, MEF actively manages the process to extract some of the more valuable long chain molecules before they are consumed and converted by the methanogens. Because MEF uses a complete ecosystem of microbes, there are a variety of chemicals and proteins produced. These include enzymes, and various fatty acids with varying concentrations. The economics of both processes can be seen in Table 1 illustrating the loss incurred by allowing acetic acid to be converted to methane. 
Table 1. Economic loss from decomposition

\begin{tabular}{|c|c|c|}
\hline Description & MEF & Anaerobic Digestion \\
\hline Formula & $\mathrm{C}_{2} \mathrm{H}_{4} \mathrm{O}_{2} \Rightarrow$ & $\mathrm{CH}_{4}+\mathrm{CO}_{2}$ \\
\hline Carbon Available for Sale & $100 \%$ & $50 \%$ \\
\hline Current Price Per Ton & $\$ 600$ & $\$ 150$ \\
\hline Time to Produce & 24 Hours & 30 days to 5 Years \\
\hline
\end{tabular}

By allowing the methanogenic bacteria to convert the various volatile fatty acids to methane, a significant economic opportunity is lost.

In the MEF process many of the products produced are in low concentrations. In the MEF process acetic, propionic, valeric, iso-valeric, butyric, iso-butyric, and hexanoic acids are produced in low concentrations. Initially, it does not make sense to process materials in very low concentrations until the financial math is done as shown in Table 2:

Table 2. Low concentrations, high revenues

\begin{tabular}{lc}
\hline Tons per day of organic waste & 1,000 \\
\hline Concentration (\%) & $0.5 \%$ \\
Tons of product per day & 5 \\
Price per ton of product (Acetic Acid) & $\$ 600$ \\
Revenue per day & $\$ 3,000$ \\
Days per year & 365 \\
Annual Revenue & $\$ 1,095,000$ \\
\hline
\end{tabular}

The issue of low concentrations is amplified when the price of the various volatile fatty acids is taken into account. VFAs can range in price from $\$ 600$ to $\$ 90,000$ per ton depending upon purity of the material. Table 3 shows some of the current prices for common industrial applications.

Table 3. Volatile fatty acids produced By MEF

\begin{tabular}{llc}
\hline Carbon & \multicolumn{1}{c}{ Description } & \$/Ton \\
\hline C2 & Acetic acid & $\$ 600$ \\
C3 & Propionic acid & $\$ 2,000$ \\
C4 & Butyric acid & $\$ 2,163$ \\
C4 & Isobutyric acid & $\$ 3,210$ \\
C5 & Valeric acid & $\$ 4,251$ \\
C5 & Isovaleric acid & $\$ 3,387$ \\
C6 & Hexanoic acid & $\$ 3,815$ \\
\hline
\end{tabular}

There are two reasons for extracting the VFAs before the methanogenic microbes convert them. The first is economic as illustrated in Tables 1,2 and 3. The second is operational. The extraction allows for a more complete fermentation. This permits more of the inbound mass/volume to be converted for either use within the process or for sale. In a fully operational system, it is estimated that less than $5 \%$ of the inbound feedstock would remain as blow-down.

In urban environments, organic waste is typically generated in the hundreds to thousands of tons per day. Organic waste typically ranges from $50 \%$ to $80 \%$ water. This means that on a dry matter basis the amount of product produced can vary considerably. Much of the test feed used to derive the data in this paper was food waste with about $80 \%$ water content. The output from the fermentation on a dry matter basis was approximately a $50 \%$ mixture of methane and carbon dioxide in a $60 / 40$ ratio. About $25 \%$ came out as proteins and long chain fatty acids. The balance was short chain fatty acids and blow-down. 
The prices shown in Table 3 are FOB China. These compounds are basic feedstock for various chemicals processes. The key economic question presented by the conversion of organic waste is what can be made from these basic chemicals that creates a higher value? Table 4 shows what can be made from the lowest value VFA, acetic acid.

Table 4. Single step chemical products from acetic acid

\begin{tabular}{llc}
\hline \multicolumn{1}{c}{ Description } & \multicolumn{1}{c}{ Application } & \$/Ton \\
\hline Acetic anhydride & Drying agent, flavoring & $\$ 715$ \\
Sodium acetate & Flavoring, tanning, concrete sealant & $\$ 790$ \\
Isopropyl acetate & Banana flavoring & $\$ 800$ \\
Acetyl chloride & Commercial chemical reagent & $\$ 1,200$ \\
Vinyl acetate & Polymers & $\$ 1,000$ \\
Acetamide & Plasticizer, industrial solvent & $\$ 1,775$ \\
\hline
\end{tabular}

MEF is a fermentation process that does generate the greenhouse gases: methane and carbon dioxide. Both of these gases are reused within the process. The methane is used to heat the process, while the carbon dioxide is used to maintain anaerobic conditions.

The conversion rate on different substrates has varied from $15 \%$ to $30 \%$ of the active volume per operating cycle. The MEF process can operate between 2 to 3 cycles per day depending upon the feedstock. In the MEF process, active volume is defined as the volume occupied by the fermentation exclusive of the headspace needed in the fermentation vessel. For example, a 1,250-liter fermentation vessel would have about 250 liters of headspace and 1,000 liters of active volume. When processing food waste, the conversion rate was about $30 \%$. This means for 1,000 liters of active volume, 300 kilos of food waste was processed per cycle each day. A two cycle per day fermentation would process $600 \mathrm{~kg}$ per day per 1,000 liters.

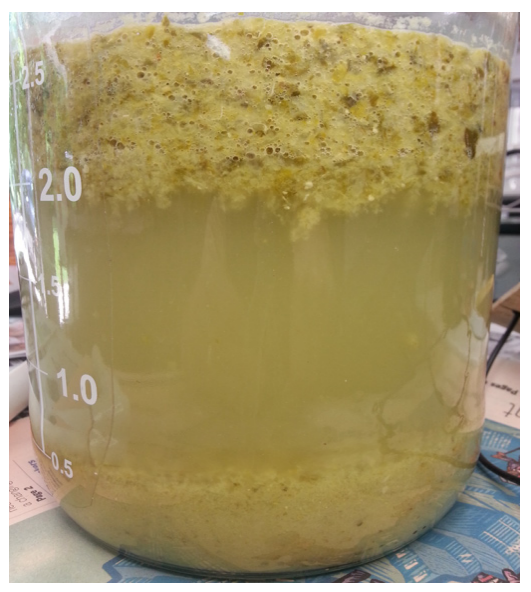

Figure 1.

The MEF process works as a stratified fermentation as seen in Figure 1.

The top mat is where the fresh feedstock is consumed. The bottom layer is where various microbes consume the waste produced in the mat. There is a continuous circulation between the bottom and mat. Essentially, all of the layers interact in such a way as to service the needs of the other by providing critical compounds needed to facilitate the fermentation. The mat contains high concentrations of enzymes that facilitate the various biochemical reactions. The bottom has high concentrations of proteins.

The production process involves the extraction of some of the bottom mat and intermediate fluid material. In this process a portion of the top mat is also removed. The separation of the various materials (or products) is accomplished by using methods and equipment in use in the food, cosmetic, pharmaceutical, and chemical industries today. These are basic processes that have worked for hundreds of years. They involve the use of commercial equipment that can be easily purchased on the open market. Transition from one feedstock to another typically takes between 60 and 120 days. Additionally, adjustments need to be made in the nutrient or microbial mix used to promote the reaction. Once the transition is completed, no additional modifications are 
needed as the process is self-sustaining. The feedstock that have been tested are shown in Table 5 .

Table 5. Tested substrates

\begin{tabular}{c}
\hline Tested Substrates \\
Food waste \\
Food waste with newsprint \\
Brewers grain \\
Food waste with brewers grain \\
Newsprint \\
Sludge from a paper mill \\
Algae (dried) \\
Cotton gin waste \\
Sewer cake \\
Sugar beet finesse
\end{tabular}

The MEF process has now been run twice for a period of over 180 days. These two tests demonstrated that the process is self-sustaining. It does not require a reinoculation. It also proved the resilience of the process. The first test was run from February 19, 2013 to August 31, 2013 (193 days). The test reactors were 3.5 liters in size. In the first test, two equipment failures occurred. There was a loss of temperature control. Temperatures went from $40^{\circ} \mathrm{C}$ to $45^{\circ}$ to $30^{\circ}$ and back to $40^{\circ} \mathrm{C}$ over a period of several days. The MEF process adapted and continued on returning to normal. The second failure occurred when $\mathrm{pH}$ control was lost for a few days. Again, the MEF process adapted and returned to normal. In the second test, larger fermentation vessels (5.5 liters) were used. It was run from January 22, 2014 through August 16, 2014 (206 days). It has become apparent in testing various substrates that the process is much more stable and productive when a larger active volume is used. Figure 2 shows the results of process over the test period. The graph shows the consistent production of acids per liter of fermentation. Essentially, processing large volumes of material can generate significant amounts of material.

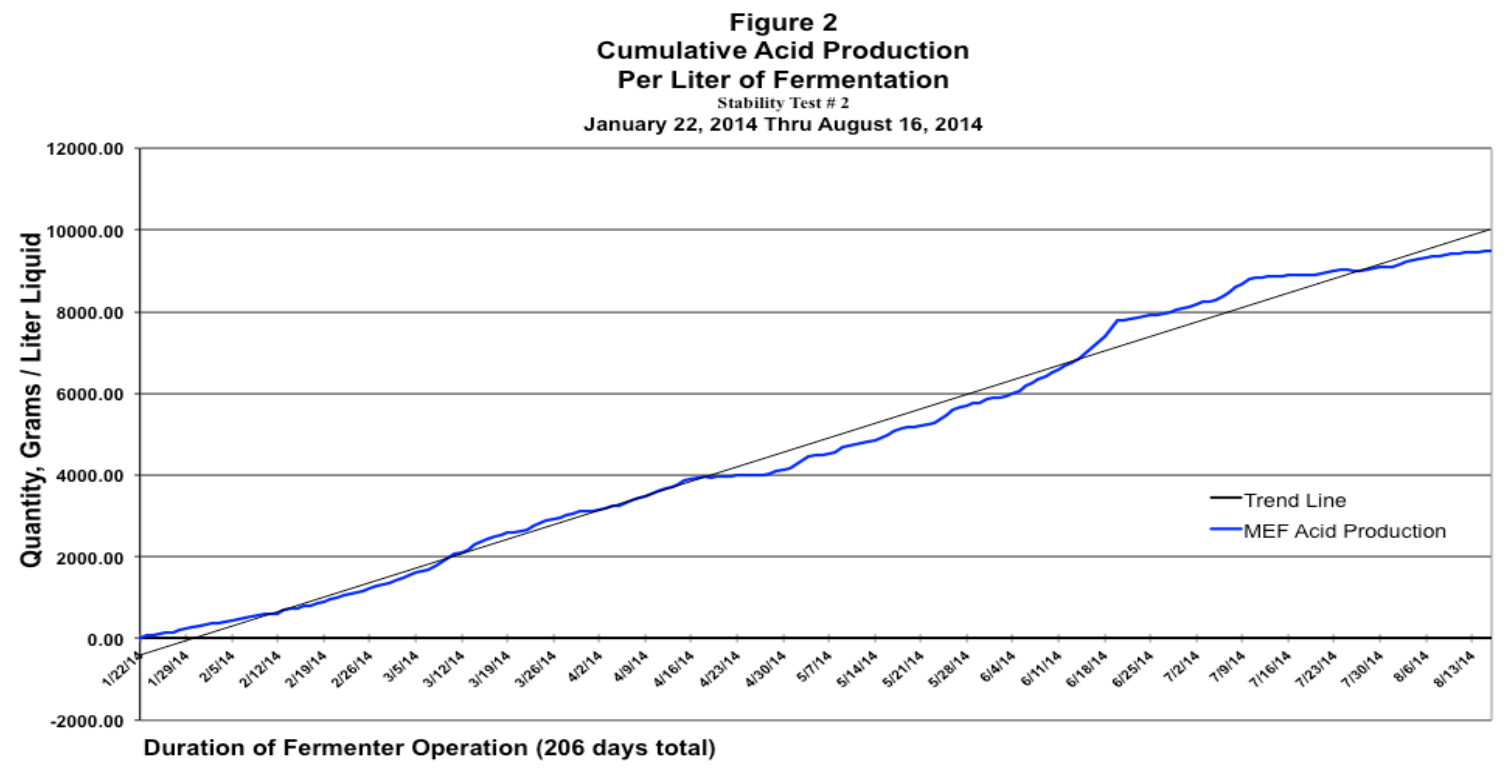

Figure 2. Cumulative acid production per liter of fermentation

The data derived under laboratory conditions suggest that the MEF process is stable and predictable. It is consistent in its production of acids. Such consistency lends itself to industrial application. The stability of the process is also illustrated in its ability to produce protein as seen in Figure 3. Figure 3 shows the protein production for the last 50 days of the second stability test. In the second stability test the average input of waste 
food per liter of fermentation was 196 grams on a wet basis (39.2 dry basis). The fermentation produced 5.12 dry grams of denatured protein per liter of fermentation per day on a single operating cycle or $13.1 \%$ conversion of dry matter. Lipid production was 2.41 dry grams or $6.1 \%$. Combined this is $19.2 \%$. This is in line with the estimated conversion rate into protein of $25 \%$ as there was substantial residual protein evident after the extraction of the protein by mechanical means. Much of the residual protein is less than 0.5 microns in size.

The MEF process produces significant amounts of microbial proteins. These proteins can be used as high protein animal feed (HPAF) or denatured for use as surfacing material in the production of paper or cardboard. Additionally, these proteins can be used in the production of adhesives. Table 6 provides the composition of this protein both as HPAF and denatured. This data was prepared by an independent animal feed laboratory.

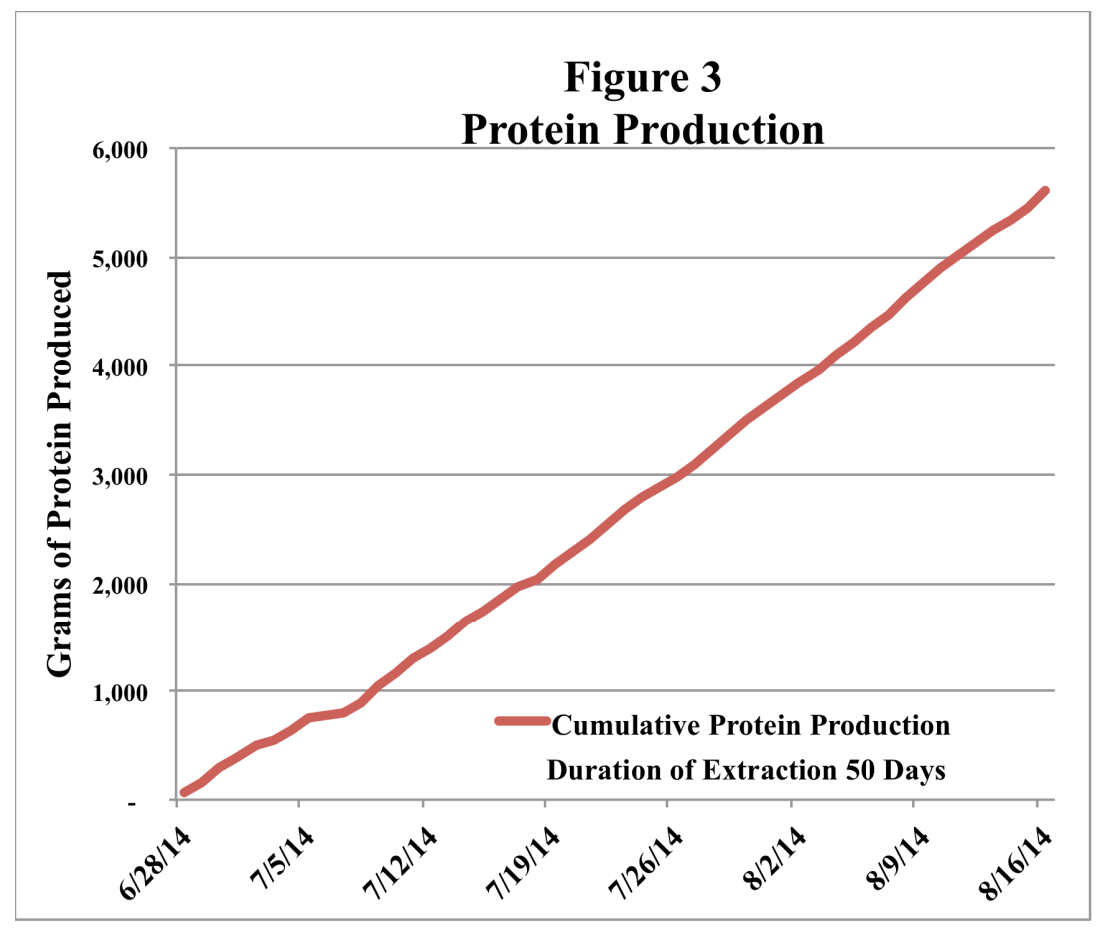

Figure 3. Protein production

Table 6. Protein produced from the MEF process

\begin{tabular}{lcc}
\hline \multicolumn{1}{c}{ Description } & HPAF & Denatured \\
\hline Moisture & $14.97 \%$ & $3.27 \%$ \\
Fat (By Acid Hydrolysis) & $31.36 \%$ & $13.81 \%$ \\
Crude Protein & $26.00 \%$ & $61.48 \%$ \\
Crude Fiber & $10.90 \%$ & $7.00 \%$ \\
Ash & $13.74 \%$ & $6.14 \%$ \\
Phosphorous & $0.90 \%$ & $0.88 \%$ \\
Pepsin Digestibility (0.2\%) & $76.42 \%$ & $80.06 \%$ \\
Carbohydrates & $13.92 \%$ & $15.30 \%$ \\
Bomb Calories (Kcal/Lb.) & 2,331 & 2,345 \\
\hline
\end{tabular}

The HPAF was denatured using a solvent. The process of denaturing the HPAF resulted in a change in the amino acid profile as shown in Table 7: 
Table 7. Amino acid profile produced by the MEF process

\begin{tabular}{|c|c|c|}
\hline Description & HPAF & Denatured \\
\hline Taurine & $0.02 \%$ & $0.06 \%$ \\
\hline Hydroxyproline & $0.00 \%$ & $0.15 \%$ \\
\hline Aspartic Acid & $2.06 \%$ & $5.45 \%$ \\
\hline Threonine & $0.94 \%$ & $2.58 \%$ \\
\hline Serine & $0.74 \%$ & $2.17 \%$ \\
\hline Glutamic Acid & $3.03 \%$ & $8.88 \%$ \\
\hline Proline & $0.80 \%$ & $3.17 \%$ \\
\hline Lanthionine & $0.06 \%$ & $0.00 \%$ \\
\hline Glycine & $0.96 \%$ & $2.59 \%$ \\
\hline Alanine & $1.54 \%$ & $3.39 \%$ \\
\hline Cysteine & $0.24 \%$ & $0.80 \%$ \\
\hline Valine & $1.40 \%$ & $3.73 \%$ \\
\hline Methionine & $0.51 \%$ & $1.42 \%$ \\
\hline Isoleucine & $1.20 \%$ & $2.94 \%$ \\
\hline Leucine & $1.81 \%$ & $4.84 \%$ \\
\hline Tryosine & $0.93 \%$ & $2.46 \%$ \\
\hline Phenylalanine & $1.07 \%$ & $3.17 \%$ \\
\hline Hydroxylysine & $0.13 \%$ & $0.07 \%$ \\
\hline Ornithine & $0.11 \%$ & $0.11 \%$ \\
\hline Lysine & $2.07 \%$ & $3.36 \%$ \\
\hline Histidine & $0.51 \%$ & $1.34 \%$ \\
\hline Arginine & $1.20 \%$ & $3.18 \%$ \\
\hline Tryptophan & $0.34 \%$ & $0.81 \%$ \\
\hline
\end{tabular}

There are several reasons for denaturing the protein. Denatured protein is worth more than two times that as HPAF. The applications for this product are surfacing material for paper and cardboard as well as use in adhesives. Second, denaturing the protein allows for the extraction of lipids. These lipids can be separated into several products. The high value lipids are called phospholipids that are used in cosmetics, lubricants, and pharmaceuticals. The remaining lipids can be then mixed with the denatured protein to provide the desired characteristics for use as HPAF. Another use would be as feedstock for the oleochemical ndustry, or for conversion into bio-diesel. Some of the compounds derived from denaturing the proteins can be seen in Tables 8 based upon independent laboratory analysis. The prices shown are FOB China.

Table 8. Carbon compounds derived from denaturing proteins

\begin{tabular}{llc}
\hline \multicolumn{1}{c}{ Carbon } & \multicolumn{1}{c}{ Description } & \$/Metric Ton \\
\hline C16.0 & Palmitic acid & $\$ 1,223$ \\
C16.1 & Palmitoleic acid & $\$ 11,294,000$ \\
C18.0 & Stearic acid & $\$ 1,311$ \\
C18.1 & Oleric acid & $\$ 2,000$ \\
C18.2N6 & Linoleic acid & $\$ 1,617,000$ \\
C18.3N3 & $\alpha$-Linolenic acid & $\$ 4,230,000$ \\
C18.3N6 & Gamma Linolenic acid & $\$ 8,065$ \\
C18.4N3 & Stearidonic acid & $\$ 2,047,000$ \\
C22.4N6 & Docosatetraenoic acid & $\$ 8,483,000$ \\
C22.5N3 & Docosapentaenoic acid $n 3$ & $\$ 9,720,000$ \\
C22.6N3 & Docosahexaenoic acid & $\$ 244,000$ \\
C24.1 & Ceramide & $\$ 1,724,000$
\end{tabular}

Among the more significant results was the ability to produce saturated and unsaturated fats as shown in Table 9. 
Table 9. Lipid composition

\begin{tabular}{lc}
\hline \multicolumn{1}{c}{ Description } & Concentration \\
\hline Saturated & $20.94 \%$ \\
Monounsaturated & $54.39 \%$ \\
Polyunsaturated & $\underline{\underline{24.67 \%}}$ \\
Total & $100.00 \%$ \\
\hline
\end{tabular}

One of the potential products to be derived from the MEF process is an adhesive as an alternative to urea formaldehyde based compounds. Tests were run on adhesives made with MEF protein with either sodium hydroxide $(\mathrm{NaOH})$ or potassium hydroxide $(\mathrm{KOH})$. Both tests involved using kraft paper tape with an approximate breaking strength of $2.81 \mathrm{~kg} / \mathrm{cm} 2(40 \mathrm{psi})$. In each tensile test series, the paper failed before the bond.

There were two other aspects about the adhesive that need to be further explored. First was the flexibility of the material. The initial observation was it remained flexible. Second, it appeared to provide a smooth surface coating that appeared to be water resistant.

One basic question remains: just how much value can be extracted from a ton of organic waste? The answer will be dependent upon the feedstock and the products produced. The two critical products are proteins and lipids. In developed countries the materials will be used for adhesives, paper production, cosmetics, and pharmaceuticals. In developing countries, these products will be used for animal feed and the production of biodiesel. Table 10 estimated the economic value of a ton of food waste as processed in a developed country. It assumes that $80 \%$ of the initial waste is water. The estimated economic value is computed by weighting the values shown in Tables 3 and 8 by their respective concentration. The products shown are only for compounds that have been verified by independent laboratories. No value has been assumed for the extraction of multiple high value enzymes like cellulase, lipase, etc. that are produced in the process.

Table 10. Estimated economic value of 1 ton of organic waste using the MEF process

\begin{tabular}{|c|c|c|c|c|c|c|c|}
\hline \multicolumn{3}{|c|}{ Primary Separation } & \multicolumn{3}{|c|}{ Secondary Separation } & \multirow[b]{2}{*}{$\begin{array}{c}\text { Weighted } \\
\text { Value Per } \\
\text { Metric Ton }\end{array}$} & \multirow[b]{2}{*}{$\begin{array}{c}\text { Potential } \\
\text { Revenue } \\
\text { Per Metric } \\
\text { Ton }\end{array}$} \\
\hline Description & $\begin{array}{c}\text { Per } \\
\text { Cent }\end{array}$ & Kg. & Description & $\begin{array}{c}\text { Per } \\
\text { Cent }\end{array}$ & Kg. & & \\
\hline Water & $80.0 \%$ & 800 & Water & $100 \%$ & 800.0 & $\$ 0$ & $\$-$ \\
\hline \multirow{2}{*}{ Gas } & \multirow{2}{*}{$10.0 \%$} & \multirow{2}{*}{100} & Methane (CH4) & $60 \%$ & 60.0 & $\$ 150$ & $\$ 9$ \\
\hline & & & Carbon Dioxide (CO2) & $40 \%$ & 40.0 & $\$ 0$ & $\$-$ \\
\hline \multirow{2}{*}{ Protein } & \multirow{2}{*}{$5.0 \%$} & \multirow{2}{*}{50} & Denatured Protein & $69 \%$ & 34.5 & $\$ 650$ & $\$ 22$ \\
\hline & & & Lipids & $31 \%$ & 15.5 & $\$ 1,233,280$ & $\$ 19,116$ \\
\hline Volatile Fatty Acids & $3.5 \%$ & 35 & Volatile Fatty Acids & $100 \%$ & 35.0 & $\$ 2,775$ & $\$ 97$ \\
\hline Blow-down & $1.5 \%$ & 15 & Blow Down & $100 \%$ & 15.0 & $\$ 0$ & $\$-$ \\
\hline Total & $100.0 \%$ & 1,000 & & & 1,000 & & $\$ 19,244$ \\
\hline
\end{tabular}

NOTES:

1) Weighted Value Per Ton is based on current market prices and weighted by concentration.

2) Potential Revenue Per Ton is assumes only two levels of separation.

3) No value has been assigned for the extraction of enzymes like cellulase, lipase, etc.

The application of the MEF process will generally be dependent upon the availability of the waste cellulosic feedstock. In most cases, it would be advantageous to locate the MEF processing equipment near the source of the waste stream to minimize the cost of transporting the waste. This is because most of the mass being transported is water. There are two reasons for this. First, it is seldom economical to transport water. Second, frequently the water can be reused at the source of the waste generation. 
The bigger issue is dependent upon local economics. For example, would it be more economically beneficial to have the process produce HPAF, feedstock for biodiesel, and methane as would be applicable in a developing economy. In a developed economy, it might be more beneficial to use the protein as adhesives, the lipids and VFA's as industrial chemicals.

$\mathrm{MEF}$ is a patented process that is designed to be integrated into existing production systems. It is analogous to an oil refinery. Oil refineries take in crude oil and convert it into multiple products based on existing market conditions using existing technology. MEF takes in organic waste/matter and biologically converts it into multiple products shifting the production based on market conditions using existing technology.

MEF produces basic industrial chemicals that are currently derived from petroleum. This creates the opportunity to redeploy the petroleum feedstock for higher value use. MEF process was developed as a means to address the organic waste issue by converting it from an economic drain into a resource. It is flexible in the feedstock it can process and can be managed to produce more desired compounds. Because MEF has removed the control systems indigenous to the animal, it is capable of producing biological compounds that are not found in the animal.

\section{References}

Calt, E. (2013, March). Converting Organic Waste to Money. Journal of Solid Waste Technology and Management.

Carolina Analytical Services, Bear Cave, North Carolina, USA 2013 \& 2014.

Hungate, R. (1966). Rumen and Its Microbes. Academic Press.

Issued US Patents 8846339, 8574370, 8367372. Canadian and European Union Patents pending.

Lipid Analytics, Guelph, Ontario, Canada 2014.

The US Department of Energy estimates there are over 30,000 enzymes in the fermentation broth. DOE Website: How now, inside the cow? 30,000 enzymes for biofuel. http://ornl.gov/info/news/pulse/no330/story4.shtml

\section{Copyrights}

Copyright for this article is retained by the author(s), with first publication rights granted to the journal.

This is an open-access article distributed under the terms and conditions of the Creative Commons Attribution license (http://creativecommons.org/licenses/by/3.0/). 